\title{
An Occupational Health Survey of British Mountain Guides Operating Internationally
}

\author{
Christian Harkensee, $\mathrm{PhD}^{1}$; David Hillebrandt, $\mathrm{MB}, \mathrm{BS}^{2}$ \\ ${ }^{1}$ Paediatric Immunology and Infectious Diseases, Queen Elizabeth Hospital, Gateshead, UK; ${ }^{2}$ Association of British Mountain Guides (ABMG), \\ Holsworthy, UK
}

Introduction-Professional mountain guides face significant occupational health risks, including injuries, accidents, environmental exposures, chronic musculoskeletal strain, and psychological stressors. This study aims to investigate these risks and their impact on the quality of life of a group of international British mountain guides.

Methods - This self-reported online survey included demographics; acute and chronic occupational conditions; and questions on general health, lifestyle, symptoms of post-traumatic stress disorder (PTSD), and quality of life based on the World Health Organization quality of life [WHOQOL-BREF] questionnaire.

Results-Responses were received from 67 (32\%) of the approached guides. Knee pain (75\%), back and neck pain (62\%), hand/upper extremity problems (51\%), and lower limb injuries (49\%) were the most commonly reported individual occupational health problems. Chronic eye problems were reported by $8 \%$, and $5 \%$ reported skin cancer. Twenty-nine percent were on regular medications, which were mainly analgesics for chronic musculoskeletal complaints. Mountain guides have a healthy lifestyle, with lower rates of being overweight/obese, alcohol consumption, and smoking than the average UK population. Fourteen $(61 \%)$ of the 23 guides responding to the PTSD questions reported experiencing life-threatening traumatic incidents, and $4(25 \%)$ of this subgroup appear to have had some symptoms of PTSD. The quality of life assessment showed that the studied mountain guides have a high quality of life.

Conclusions-Musculoskeletal problems are the main occupational health problems experienced by the study group. New findings include a low but important prevalence of ultraviolet radiation-associated conditions. One in 3 guides have experienced significant psychological trauma, and one quarter of these had symptoms of PTSD.

Keywords: lifestyle, environmental exposure, quality of life, lower extremity, stress disorder, posttraumatic

\section{Introduction}

International mountain guides are a small professional group, yet the profession carries potentially high occupational health risks. Mountain guides are exposed to environmental risks including rock fall, avalanche, falls on steep ground, extremes of temperature, altitude, and ultraviolet (UV) light exposure. They are also known to experience, more so than the general population, ${ }^{1}$ acute and chronic musculoskeletal problems, particularly knee and hip pain. Physical symptoms, a high level of responsibility

Corresponding author: David Hillebrandt, MB, Derriton House, Holsworthy EX226JX, UK; e-mails: dh@ hillebrandt.org.uk; hillebrandt@freenetame.co.uk.

Submitted for publication August 2018.

Accepted for publication March 2019. for clients, constantly changing and often difficult risk management, and experience of trauma (their own and that of colleagues, clients, and other mountaineers) are potential risk factors for the development of emotional stress and mental health problems. Because most mountain guides are self-employed, physical and mental stress affects their ability to earn, which itself can further add to the stress.

A self-reported survey of British mountain guides operating internationally under the auspices of the International Federation of Mountain Guides Association (IFMGA), also known under its French title of the Union Internationale des Associations de Guides de Montagnes, was undertaken in 2006 and published in $2007 .^{2}$ It indicated that $86 \%$ reported ongoing musculoskeletal problems (two-thirds lower limb, one-third on upper limb), 
$9 \%$ had acute medical problems related to their profession, $15 \%$ had chronic medical conditions, and $8 \%$ reported a mental health issue (stress, depression, substance misuse). A similar survey was performed on high altitude Nepali climbing "guides" 3 (as opposed to qualified Nepali IFMGA guides), among whom respiratory (60\%) and musculoskeletal (55\%) symptoms were dominant; $25 \%$ reported exposure to accidents. No comprehensive data on mountain guide occupational health are available from continental Europe, although a few studies report on specific issues: skin exposure to high UV radiation and consequences such as risk of skin cancer, seborrheic dermatitis, ${ }^{4-7}$ and eye disease, ${ }^{8,9}$ as well as psychological adaptation to experienced trauma. ${ }^{10,11}$ One case report describes a case of deep vein thrombosis in a mountain guide, highlighting specific risk factors and management. ${ }^{12}$ Causes, symptoms, risk factors, and management of acute mountain sickness, high altitude pulmonary edema (HAPE), and high altitude cerebral edema (HACE) have been described extensively in the literature, ${ }^{13-16}$ albeit not specifically for mountain guides.

The purpose of this study was to investigate the community of British mountain guides for occupational health risks and conditions and their effect on quality of life in order to understand current issues and make informed recommendations on management and prevention of occupational diseases.

\section{Methods}

This study was a self-reported health survey of mountain guides operating internationally under the IFMGA scheme (targeting the same population as in the previous 2007 study), ${ }^{2}$ applied as an online questionnaire through a web-based platform (SurveyMonkey). The study plan was reviewed and approved by the research department of North Tees and Hartlepool NHS Trust and classed as exempt from the requirement for individual informed consent.

The survey questionnaire encompassed 3 sections. The first, nonstandardized section included baseline demographic data; details of any acute and chronic health conditions, present and past; and lifestyle and work conditions. This incorporated questions from the previous survey ${ }^{2}$ and from routine occupational health questionnaires from the literature. ${ }^{17-19}$ The second section inquired about symptoms of post-traumatic stress disorder (PTSD). To keep the questionnaire short, PTSD was explored by a simple symptom checklist according to the classification of PTSD rather than with standardized tools. ${ }^{10}$ The third section consisted of the 26-item World Health Organization quality of life (WHOQOL-
BREF) questionnaire, which is a standardized tool ${ }^{20}$ that assesses quality of life across 4 domains: physical health (activities of daily living, dependence on medicines and medical aids, energy and fatigue, mobility, pain and discomfort, sleep and rest, work capacity), psychological health (bodily image and appearance, negative/positive feelings, self-esteem, spirituality and personal beliefs, thinking, learning, memory, concentration), social relationships (personal relationships, social support, sexual activity), and environment (financial resources, freedom, safety, security, access and quality of social and healthcare, home environment, opportunities for acquiring new information and skills, opportunities and participation in leisure/recreation, physical environment, and transport).

The questionnaire was piloted on 3 mountain guides, and their feedback was incorporated in the final version. The survey was administered through an e-mail message to all registered members of the Association of British Mountain Guides (ABMG), providing an information leaflet and a link to the SurveyMonkey questionnaire. Repeated reminder e-mails were sent through the same forum over the survey period (November 2016 to May 2017). The target population (sampling frame) included all active guides, full-time/part-time workers, trainee and aspirant guides, and retired guides registered with ABMG $(n=208)$.

We tested for a statistically significant association between the most common occupational and nonoccupational health conditions (knee pain, back and neck pain, hand and finger problems, muscle and joint pains) and quality of life (tested: third and fourth quartile vs first and second quartile; fourth quartile vs first, second, and third quartile).

After closure of the survey, data were extracted from SurveyMonkey and collated in an Excel (Microsoft Corp) spreadsheet. Statistical analyses were performed in Excel and through import into SPSS v17 (SPSS Inc). Fisher exact test was used for hypothesis testing, with a significance level of $P<0.05$ required for an association to be determined statistically significant. Odds ratios (ORs) were calculated with $95 \%$ confidence intervals.

\section{Results}

The baseline demographics of the surveyed population are summarized in Table 1 . The survey remained open for 7 mo to enable guides who were away on protracted trips to reply. The response rate from the 208 members of the association was $32 \%(n=67)$, which did not reach the response rate of the 2007 survey (51\%). Data completion was high, with $97 \%$ of all possible data points completed by respondents. Demographics were largely similar between the 2007 and 2016 surveys, although we noted that fewer guides operate at altitudes $>7000 \mathrm{~m}$ in 
Table 1. Baseline demographics of the 67 guides surveyed

\begin{tabular}{|c|c|c|}
\hline 2016 survey variables & $n$ & $\%$ \\
\hline Survey return rate & 67 & 32 \\
\hline Male & 59 & 88 \\
\hline Female & 6 & 9 \\
\hline \multicolumn{3}{|l|}{ Age, y } \\
\hline $30-39$ & 8 & 12 \\
\hline $40-49$ & 17 & 25 \\
\hline $50-59$ & 29 & 43 \\
\hline $60-69$ & 9 & 13 \\
\hline$\geq 70$ & 3 & 5 \\
\hline Aspirant & 1 & 1 \\
\hline Trainee guide & 1 & 1 \\
\hline Fully qualified guide & 59 & 88 \\
\hline Retired guide & 5 & 7 \\
\hline Employed, full time & 3 & 4 \\
\hline Employed, part time & 1 & 1 \\
\hline Self-employed, full time & 40 & 60 \\
\hline Self-employed part time & 13 & 19 \\
\hline Not currently working & 3 & 4 \\
\hline Other & 6 & 9 \\
\hline Mean guiding experience, $y$ & & \\
\hline Mean no. of years qualified & & \\
\hline \multicolumn{3}{|l|}{ No. of work categories } \\
\hline 1 & 6 & 9 \\
\hline 2 & 19 & 28 \\
\hline 3 & 17 & 25 \\
\hline 4 & 12 & 18 \\
\hline 5 & 6 & 9 \\
\hline 6 & 2 & 3 \\
\hline 7 & 3 & 4 \\
\hline \multicolumn{3}{|l|}{ No. of ranges } \\
\hline 1 & 12 & 18 \\
\hline 2 & 34 & 51 \\
\hline 3 & 7 & 10 \\
\hline 4 & 5 & 7 \\
\hline 5 & 1 & 1 \\
\hline 6 & 6 & 9 \\
\hline \multicolumn{3}{|c|}{ No. $d$ spent in mountains in last 1 y 158 (range $0-320$; SD 83) } \\
\hline Highest altitude $>8000 \mathrm{~m}$ & 11 & 16 \\
\hline \multicolumn{3}{|l|}{ Highest altitude } \\
\hline Everest $(8850 \mathrm{~m})$ & 6 & 9 \\
\hline Highest altitude $7000-7999 \mathrm{~m}$ & 17 & 25 \\
\hline Highest altitude $6000-6999 \mathrm{~m}$ & 33 & 49 \\
\hline Highest altitude $5000-5999 \mathrm{~m}$ & 3 & 4 \\
\hline Highest altitude $<5000 \mathrm{~m}$ & 2 & 3 \\
\hline
\end{tabular}

Aspirant guide: recently qualified guide who can guide under supervision only.

Trainee guide: not yet qualified to work with clients.

Work categories include alpine guiding, ski mountaineering, big walls, greater ranges, commercial expeditions, filming, and other (winter climbing, ice climbing, polar expeditions, consultancy, lecturing/ teaching/assessing, writing guide books, avalanche forecasting).

Ranges include UK, Europe, Himalaya and Karakoram, other Central Asian ranges, south and southeast Asia and Australia, North and Central America, South America, Antarctica. the 2016 survey (data not shown). The majority of guides worked in 2 mountain areas, predominantly in the UK and in the Alps.

Table 2 shows the self-reported work-related and non-work-related health conditions. The majority of our respondents $(n=49 ; 73 \%)$ stated that they took no medication on a regular basis. Eighteen reported regular use, and this was predominantly simple analgesics such paracetamol or nonsteroidal anti-inflammatory (NSAID) drugs. Nine of the prescriptions were for nonsteroidal anti-inflammatories ( $42 \%$ of those on prescribed medication and $13 \%$ of the guides overall). Other prescription drugs included thyroxine $(n=3)$, ranitidine, asthma inhalers, allopurinol, enalapril, bendroflumethiazide (diuretic used in the UK to treat hypertension), omeprazole, simvastatin, lisinopril, paroxetine, finasteride, ramipril, sumatriptan, and loratadine of respondents ( $\mathrm{n}=1$ each).

Seventy-two percent of respondents had a normal body mass index (BMI), $18 \%$ were overweight, and 2 were obese. Only 4 smoked. Alcohol consumption was 12.6 units. $\mathrm{wk}^{-1}$ average per guide (range $0-50$ units. $\mathrm{wk}^{-1}$ ). Four respondents $(6 \%)$ did not drink at all, $69 \%$ drank alcohol but within recommended limits (14 units $\mathrm{wk}^{-1} ; 1$ unit $=8 \mathrm{~g}$ of pure alcohol), and $18 \%$ had a weekly alcohol consumption that exceeded UK recommended limits.

When asked about which activities most adversely affected their well-being, guides reported that walking downhill (36\%) and lengthy walking, standing, lifting, and carrying (26\%) affected them "very much" or "quite a lot." The average total number of working days lost for health reasons due to mountain-related activity was 25 (range 0-350) for each of the 61 respondents during their working life and 11 days $(0-270)$ for non-mountain-work-related health problems. Twenty-three (34\%) guides responded to the screening questions for PTSD, and the results are summarized in Table 3.

In the WHOQOL-BREF quality of life questionnaire, respondents scored above a British reference population in all 4 domains (Table 4). In the direct quality of life question within WHOQOL, 98\% of respondents said their quality of life was either very good (63\%) or good (35\%), and only $2 \%$ said neither poor nor good. Eighty-four percent stated their health was good or very good, $10 \%$ neither good nor poor, and $7 \%$ poor. When looking at mood, anxiety, or depression, 30\% said they never experienced problems, $52 \%$ said seldom, $18 \%$ said quite often, and 1 said very often. In relation to the question of how satisfied guides are with access to healthcare, $30 \%$ said very satisfied, 38\% satisfied, $20 \%$ neither satisfied nor dissatisfied, $8 \%$ dissatisfied, and $5 \%$ very dissatisfied.

There was no statistically significant association between the most common occupational and 
Table 2. Episodes of acute mountain-related/non-mountainrelated conditions as reported by the 67 surveyed mountain guides

\begin{tabular}{lcc}
\hline Conditions & $n$ & $\%$ \\
\hline \multicolumn{1}{c}{ Mountain guide work-related acute } & illness & and \\
\hline Lower limb injury & 31 & 49 \\
Shoulder injury & 22 & 35 \\
Altitude sickness & 21 & 33 \\
Sunburn & 20 & 32 \\
Upper limb injury & 18 & 29 \\
Rib/Chest injury & 17 & 27 \\
Frostbite & 14 & 22 \\
Head injury & 11 & 18 \\
Spinal injury & 11 & 18 \\
Snow blindness & 11 & 18 \\
Polytrauma & 9 & 14 \\
Internal injury & 6 & 10 \\
HAPE & 6 & 10 \\
Pelvic injury & 5 & 8 \\
Heat-related illness & 5 & 8 \\
HACE & 2 & 3 \\
Hypothermia & 1 & 2 \\
\hline
\end{tabular}

Chronic conditions and symptoms

\begin{tabular}{lll} 
Knee pain & 47 & 75 \\
Back/Neck pain & 39 & 62 \\
Hand/Finger problems & 32 & 51 \\
Shoulder pain & 29 & 47 \\
Ankle pain & 23 & 37 \\
Foot problems & 17 & 27 \\
Other chronic problems & 16 & 25 \\
Chronic eye problems & 5 & 8 \\
Skin cancer & 3 & 5 \\
\hline
\end{tabular}

Non-work-related medical illness and mental health

Muscle and joint problems

$\begin{array}{ll}15 & 24 \\ 10 & 16 \\ 10 & 16 \\ 7 & 11 \\ 7 & 11 \\ 7 & 11 \\ 7 & 11 \\ 7 & 11 \\ 6 & 10 \\ 6 & 10 \\ 6 & 10 \\ 5 & 8 \\ 3 & 5 \\ 2 & 5 \\ 2 & 5 \\ 2 & 5\end{array}$

Fatigue

ENT problems

Depression/Stress

Sleep problems

Autoimmune, rheumatism

Skin problems

Gastrointestinal problems

Chest problems

Eye problems

Infections

Sequelae of injuries

Kidney/Bladder problems

Hormonal problems

Heart and blood pressure problems

Headaches

HAPE, high altitude pulmonary edema; HACE, high altitude cerebral edema; ENT, ear, nose, and throat.

$\mathrm{n}=$ proportion of mountain guides reporting to have experienced the type of condition. nonoccupational health conditions and quality of life (data not shown).

\section{Discussion}

This survey found that the majority of the responding British mountain guides have occupational health issues that may affect their ability to work. At the same time, the responding mountain guides enjoy a high quality of life that does not seem to be affected significantly by ill health.

The most frequently reported problems were acute and chronic musculoskeletal complaints. Because their work involves prolonged hard physical activity over many years and constant exposure to potential accidents both when working or at leisure, this is not surprising. Although disease status for osteoarthritis was not determined, the high frequency of symptoms in mountain guides may suggest that the prevalence of symptomatic osteoarthritis may be higher than in the overall population of a developed country. ${ }^{21,22}$ Every guide in our study reported at least 1 significant musculoskeletal problem, either through acute injury or chronic complaints. There was no difference in guides' age for onset of these musculoskeletal problems, which may suggest that the consequences of acute injuries as well as wear from long-standing physical activity may contribute. We note that $18 \%$ of the responding guides had a spinal injury, $10 \%$ had an injury to the internal organs, and $49 \%$ had injuries/fractures of the lower limbs. Similar figures were obtained in the 2007 article. $^{2}$ The Sherpa "guides" referred to by Macdonald et $\mathrm{al}^{3}$ had a 55\% incidence of musculoskeletal problems. Twelve guides in our study (19\%) had had orthopedic surgery, and 7 of

Table 3. Symptoms of PTSD experienced by mountain guides after a traumatic event

\begin{tabular}{lc}
\hline PTSD symptoms & $n(\%)$ \\
\hline Guide experienced event him/herself & $15(65)$ \\
Guide was witness to event & $12(52)$ \\
The event was perceived as life-threatening & $14(61)$ \\
Since the event, avoids similar situations & $10(43)$ \\
Since the event, experiences flashbacks & $6(26)$ \\
Since the event, feels more hypervigilant & $5(22)$ \\
Since the event, has memory problems & $5(22)$ \\
Since the event, feels more irritable & $3(13)$ \\
Since the event, has sleep problems & $3(13)$ \\
Since the event, gets easily startled & $2(9)$ \\
Since the event, has concentration problems & $1(4)$
\end{tabular}

PTSD, post-traumatic stress disorder.

Twenty-three of the responding guides (34\%) reported such an event at some point in their career. 
Table 4. Result scores of WHOQOL-BREF, and comparison with a UK reference population

\begin{tabular}{lccc}
\hline Domain & UK reference population & UK mountain guide survey 2016 & Difference \\
\hline 1. Physical & 73.5 & 80 & +6.5 \\
2. Psychological & 70.6 & 77 & +6.4 \\
3. Social & 71.5 & 75 & +3.5 \\
4. Environment & 75.1 & 77 & +1.9 \\
\hline
\end{tabular}

these were for an anterior cruciate ligament (ACL) tear (11\%), although only $4(5 \%)$ had ACL surgery in the 2007 group. The ACL tear frequency in competitive skiers is higher, a figure of $28 \%$ being obtained in 1 study $^{23}$ over 25 y and 379 athletes. The general population of the United States has an annual incidence of 1 in $3500(0.03 \%)$, or $0.7 \%$, over $25 \mathrm{y}$. The consequences of ACL tears in relation to loss of income and the development of post-ACL tear arthritis are likely to be significant.

Medical issues, such as autoimmune diseases and rheumatism, sleep problems, lung and chest problems, and skin conditions had a relatively low incidence but merit comment because they could be prevented, may have a major effect on ability to work, or should be kept in mind in terms of differential diagnosis. Lyme disease and gastrointestinal infections such as amoebic dysentery, salmonella, and giardiasis could be considered occupational health risks with potential long-term implications.

Respondents reported a high level of satisfaction with their work. However, $12 \%$ had problems with depression, stress, or other psychological/psychiatric problems, which is similar to the incidence of $11 \%$ reported in 2007 .

Chronic eye problems due to sun exposure affected $8 \%$, although none of the 2007 group reported such problems. Skin cancer affected $5 \%$ of the guides, with UV exposure being a known causative factor. However, to put this into perspective, $2 \%$ of Caucasians develop skin cancer in their lifetime. ${ }^{24}$ Eleven percent of the guides had experienced HAPE and/or HACE, which is higher than the 6\% reported in 2007. All of the guides in the 2007 study had climbed above $4000 \mathrm{~m}$, and 30 had been above $7000 \mathrm{~m}$. The figures could be partly explained by the preference $87 \%$ of the guides expressed for climbing on alpine peaks; only $26 \%$ preferred climbing in the Himalaya and Karakoram, with the associated risks of altitude-related illness. No episodes of frostbite were reported in 2007, so the 14 episodes of frostbite and 2 of frostnip in this study were unexpected, especially when one considers the improvements in clothing over the intermediate years. This may be due to previous underreporting, but it would be useful to obtain further information about the likely causation.
Mountain guides have high rates of prescriptions for NSAIDs. Frequent use of NSAIDs correlates with the high incidence of musculoskeletal problems. We do not know the amount of self-medication with over-thecounter NSAIDs. Minimal therapy for hypertension or asthma seems to indicate a low incidence of these diseases, but the active population with few smokers may be a relevant factor.

Overall, our guide group reported good lifestyle indicators. Despite one-third feeling affected by walking downhill and one quarter reporting effects of lengthy walking, standing, carrying loads, and levels of stress and depression, sickness-related work absences were low. Twenty-one percent of responding guides were overweight or obese (compared with $54 \%$ of the UK adult population). Because we did not evaluate body fat proportion, we are unable to determine whether higher BMI represents higher muscle mass or fat mass. High BMI, however, does represent a risk for lower limb joint problems. Alcohol consumption exceeding recommended levels (18\%) and the rate of smoking (6\%) were also below UK average levels (31\% and 16\%, respectively).

Thirteen percent of the guides said that they were very dissatisfied or dissatisfied with their access to healthcare. It was unclear whether this applied to when they were in the UK or abroad and whether it applied to general practice services in the community or hospital care.

Twenty-three (37\%) of the guides answered the block of questions relating to PTSD. More than half $(n=41$; $61 \%$ ) experienced own or partner/client incidents that they perceived as life-threatening. Approximately 25\% of these guides have single or combined symptoms as experienced in PTSD, such as avoidance behavior, flashbacks, and memory and sleep problems. This is in keeping with the literature, ${ }^{25,26}$ although we did not survey the duration of symptoms. A study from Switzerland ${ }^{10}$ found that the PTSD rate in mountain guides was low compared to the general population and to other highrisk professions, indicating a high degree of psychological resilience in the guiding community. The ABMG has trained several senior guides in trauma risk management counseling techniques, as used in the UK military, in an 
attempt to reduce the incidence of PTSD after being involved in a traumatic event.

It is rare for $98 \%$ of the members of a profession to be able to say their quality of life is good or very good. This most likely reflects the enthusiasm required by any guide embarking on the initial training scheme. This quality of life score indicates high motivation to continue enjoying work, despite consistent histories of joint and muscle aches and trauma. The quality of life of mountain guides as informed by the WHOQOL-BREF appears favorable when compared to a standard UK population. ${ }^{27}$ It is important to note that the chronic physical health conditions reported, such as musculoskeletal problems, do not affect the physical and overall quality of life, and there was no association between lower quartiles of quality of life and any of the physical health outcomes.

\section{STUDY LIMITATIONS}

This study attempted a comprehensive survey encompassing both physical and psychological health and quality of life for guides. It achieved a response with high data completeness (97\% of data points complete) but a low response rate. This rate of participation was lower than in the previous survey and may have introduced bias. We do not know the reasons for nonresponse or the health status in nonresponders. The lower response rate could over- or underestimate true rates of occupational health problems or quality of life. The voluntary nature of the survey may have resulted in a responder and volunteer bias ("healthy" guides may have been less inclined to respond), and the length and intensity of the survey may have discouraged participants, whether healthy or not (we excluded 6 participants who registered but never entered any data). It would be useful to design the survey in a way that would encourage "healthy" guides to participate and allow them to "fast track" through illness-related questions.

Because the survey was self-reported and anonymous, we had no means of verifying information. The question set consisted mainly of nonstandardized questions, which we felt was difficult to avoid. There are no standardized questionnaires for this profession in the literature, and the very small sampling frame is likely to prevent derivation of meaningful and robust standard deviations. The use of ordinal data scales, because of their nature, may merely represent an approximation of what was intended to be measured. In this survey, we intended to explore the frequency of PTSD symptoms, which does not allow us to estimate the frequency of PTSD; however, the number of responses indicates that there is a need to investigate this further. With regard to the WHOQOL-BREF, there are some limitations to these
Table 5. Health recommendations for mountain guides

Recommendations for mountain guides and health professionals

- More experienced guides serve as role models for younger guides by adopting (or not adopting) health preventative measures.

- Mountain guides should have adequate accident and health insurance to cover their needs.

- Awareness of mechanisms and behavior that lead to chronic musculoskeletal conditions and their prevention from early in a guide's career (eg, use of trekking poles, ${ }^{27}$ top-quality load-distributing rucksacks, and the lightest possible loads; pre-exercise warm-up periods).

- Eye protection: wearing sun hats and quality sunglasses at high altitude, regular check-ups with an optometrist/ ophthalmologist.

- Skin cancer prevention: protective clothing, hats, high protective factor sunscreen, and awareness of warning signs for premalignant and malignant skin changes; regular skin checks by the general practitioner or a dermatologist.

- Adequate physical and mental rest periods after exertion.

- If regular analgesia is used, getting advice from general practitioner on choice of medication, doses, and prevention of gastrointestinal problems.

- Awareness of PTSD signs and symptoms; knowing how to obtain professional help.

- Always allowing time for altitude acclimatization.

- Awareness and prevention of cold injuries and how to contact the specialist UK frostbite and cold injury service administered by the British Mountaineering Council (https://www.thebmc.co.uk/how-to-get-expert-frostbiteadvice? $\mathrm{s}=4)$.

Recommendations for mountain guides, health professionals, and mountain guide organizations

- Develop an occupational health advice service for both prevention and treatment using experienced mountain medicine physicians and physiotherapists. Provide advice on adequate health and accident insurance.

- Lobby for certain common or serious conditions to be recognized as occupational diseases - connect and collate the expertise and evidence.

- Review the pathway for support after trauma-ensure early psychological debriefing and access to a mental health professional if required.

PTSD, post-traumatic stress disorder.

results because the mountain guide population is different from the standard UK population. These include differences in sex (mountain guides are predominantly male), age (underrepresentation of $<30 \mathrm{y}$ and $>60 \mathrm{y}$ ), and employment status (most mountain guides work). Ability to work is known to be associated with better health ("healthy worker effect"), and a population that is unable to work because of ill health may be underrepresented in our sample. 
Further research into occupational health problems of mountain guides is necessary to provide more robust advice on preventing and managing occupational disease in mountain guides.

\section{Conclusions}

Musculoskeletal injuries and chronic musculoskeletal conditions are the main occupational health issues faced by the studied British mountain guides working internationally. Compared to a previous survey conducted $10 \mathrm{y}$ earlier, this study identified chronic eye and skin problems as well as psychological problems after experiencing a major trauma as new issues that need to be addressed in prevention and treatment (Table 5). ${ }^{27}$ Despite a large number of mountain guides experiencing health issues, the overall quality of life is good.

Acknowledgments: The authors pay tribute to their colleague, Dr Adrian Clifford, who as a candidate on the UK Diploma of Mountain Medicine helped conceive the study and carried out data collection and initial analysis. Adrian, a GP from Keswick in the Lake District, was one of the United Kingdom's most eminent expedition and mountain rescue doctors and an experienced mountaineer. He was a participant of Mal Duff's legendary Mustagh Tower Expedition in 1984. Sadly, Adrian died unexpectedly in 2017, and $\mathrm{CH}$ and DH completed this work in memory of their friend and colleague.

The authors thank the Association of British Mountain Guides (ABMG) for agreeing to support this project, all the members who kindly gave up time to complete our survey, and Corrina Parry in the guide's office in Capel Curig for answering so many little questions.

Author Contributions: Study conception and design $(\mathrm{CH})$; conducted the survey and data collection $(\mathrm{CH})$; drafted manuscript $(\mathrm{CH}, \mathrm{DH})$; completed the manuscript $(\mathrm{CH}, \mathrm{DH})$.

Financial/Material Support: None.

Disclosure: DH is the honorary medical advisor to the BMGA.

\section{References}

1. Palmer KT, Goodson N. Ageing, musculoskeletal health and work. Best Pract Res Clin Rheumatol. 2015;29 (3):391-404.

2. Hillebrandt D. Occupational health problems of British mountain guides operating internationally. J Brit Travel Health Assoc. 2007;10:43-7.

3. Macdonald EB, Shrestha S, Chhetri MK, Sherpa LR, Sherpa da G, Murray K, et al. Work-health needs of highaltitude mountain guides (Sherpas) in Nepal - a pilot study. Int J Occup Saf Ergon. 2015;21(1):9-14.

4. Bauer A, Beissert S, Knuschke P. Prevention of occupational solar UV radiation-induced epithelial skin cancer [in German]. Hautarzt. 2015;66(3):173-8.

5. Lichte V, Dennenmoser B, Dietz K, Hafner HM, Schlagenhauff $\mathrm{B}$, Garbe $\mathrm{C}$, et al. Professional risk for skin cancer development in male mountain guides-a cross-sectional study. J Eur Acad Dermatol Venereol. 2009;24(7):797-804.

6. Moehrle M, Dennenmoser B, Garbe C. Continuous longterm monitoring of UV radiation in professional mountain guides reveals extremely high exposure. Int $J$ Cancer. 2003;103(6):775-8.

7. Moehrle M, Dennenmoser B, Schlagenhauff B, Thomma S, Garbe C. High prevalence of seborrhoeic dermatitis on the face and scalp in mountain guides. Dermatology. 2000;201 (2):146-7.

8. El Chehab H, Blein JP, Herry JP, Chave N, Ract-Madoux G, Agard E, et al. Ocular phototoxicity and altitude among mountain guides [in French]. J Fr Ophtalmol. 2012;35 (10):809-15.

9. McIntosh SE, Guercio B, Tabin GC, Leemon D, Schimelpfenig T. Ultraviolet keratitis among mountaineers and outdoor recreationalists. Wilderness Environ Med. 2011;22(2):144-7.

10. Sommer I, Ehlert U. Adjustment to trauma exposure: prevalence and predictors of posttraumatic stress disorder symptoms in mountain guides. J Psychosom Res. 2004;57 (4):329-35.

11. Carey P, Seedat S. Adjustment to trauma exposure in mountain guides. J Psychosom Res. 2004;57(4):337-8.

12. Hull CM, Rajendran D, Fernandez Barnes A. Deep vein thrombosis and pulmonary embolism in a mountain guide: awareness, diagnostic challenges, and management considerations at altitude. Wilderness Environ Med. 2015;27(1):100-6.

13. Davis PR, Pattinson KT, Mason NP, Richards P, Hillebrandt D. High altitude illness. J R Army Med Corps. 2011;157(1):12-7.

14. Imray $\mathrm{C}$, Booth A, Wright A, Bradwell A. Acute altitude illnesses. BMJ. 2011;343:d4943.

15. Imray C, Wright A, Subudhi A, Roach R. Acute mountain sickness: pathophysiology, prevention, and treatment. Prog Cardiovasc Dis. 2010;52(6):467-84.

16. Zafren K. Prevention of high altitude illness. Travel Med Infect Dis. 2014;12(1):29-39.

17. Ehrenberg RL. Use of direct surveys in the surveillance of occupational illness and injury. Am J Public Health. 1989;79(suppl):12-4.

18. Ehrenberg RL, Sniezek JE. Development of a standard questionnaire for occupational health research. Am J Public Health. 1989;79(suppl):15-7.

19. Weel AN, Fortuin RJ. Design and trial of a new questionnaire for occupational health surveys in companies. Occup Med (Lond). 1998;48(8):511-8.

20. World Health Organization. WHOQOL-BREF-Introduction, Administration, Scoring and Generic Version of the Assessment. Geneva: WHO; 1996.

21. Zhang Y, Jordan JM. Epidemiology of osteoarthritis. Clin Geriatr Med. 2010;26(3):355-69.

22. Litwic A, Edwards MH, Dennison EM, Cooper C. Epidemiology and burden of osteoarthritis. $\mathrm{Br}$ Med Bull. 2013;105:185-99.

23. Pujol N, Blanchi MP, Chambat P. The incidence of anterior cruciate ligament injuries among competitive Alpine skiers: a 25-year investigation. Am J Sports Med. 2007;35 (7):1070-4.

24. Apalla Z, Lallas A, Sotiriou E, Lazaridou E, Ioannides D. Epidemiological trends in skin cancer. Dermatol Pract Concept. 2017;7(2):1-6. 
25. Kessler RC, Sonnega A, Bromet E, Hughes M, Nelson CB. Posttraumatic stress disorder in the National Comorbidity Survey. Arch Gen Psychiatry. 1995;52(12):1048-60.

26. Creamer M, Burgess P, McFarlane AC. Post-traumatic stress disorder: findings from the Australian National
Survey of mental health and well-being. Psychol Med. 2001;31(7):1237-47.

27. Hawthorne G, Herrmann H, Murphy B. Interpreting the WHOQOL-BREF: preliminary population norms and effect sizes. Soc Indic Res. 2006:(77):37-59. 